\title{
MARKETING SOCIAL E SUA INFLUÊNCIA NO BRANDING E NA RELAÇÃO COM STAKEHOLDERS: O CASO DO PROGRAMA JOVEM APRENDIZ DO CIEE - RORAIMA
}

\author{
SOCIAL MARKETING AND ITS INFLUENCE ON BRANDING AND RELATIONSHIP WITH \\ STAKEHOLDERS: THE CASE OF CIEE'S YOUNG APPRENTICE PROGRAM - RORAIMA
}

Recebido em 30.10.2020 Aprovado em 23.11.2020 Avaliado pelo sistema double blind review DOI: https://doi.org/10.32888/cge.v8i3.46991

\author{
Inaê Iandara Moraes de Andrade Huppes \\ ina-moraes@outlook.com \\ Universidade Estadual de Roraima - Departamento Ciências Socialmente Aplicadas - Curso de Administração \\ orcid.org/0000-0002-7089-0454
}

Jacquelaine Alves Machado

jacquelaine.alves@,uerr.edu.br

Universidade Estadual de Roraima - Departamento Ciências Socialmente Aplicadas - Curso de Administração orcid.org/0000-0002-5523-6876

\begin{abstract}
Resumo
O estudo teve como objetivo analisar a influência do marketing social, direcionado ao programa jovem aprendiz do CIEE Boa Vista - RR, no branding e na relação com os stakeholders da instituição. Como procedimentos metodológicos utilizou-se a pesquisa bibliográfica, documental e entrevistas estruturada e semiestruturada, além de observação direta realizada nas dependências das organizações parceiras. Os resultados alcançados foram capazes de responder aos objetivos estabelecidos. Verificou-se que houve mais retorno positivo quanto aos impactos causados pelo Programa Aprendiz tanto na vida dos jovens participantes, quanto para o stakeholders e marca vinculada a esses, assim como o agente intermediador.
\end{abstract}

Palavras-chave: Marketing Social. Branding. Stakeholders.

\begin{abstract}
The study aimed to analyze the influence of socialmarketing, directed to the Young apprentice program of CIEE Boa Vista - RR, branding and the relationship with the institution's stakeholders. As methodological procedures used bibliographic research, documentary, structured and semi-structured interviews, in addition to direct observation carried out on the premises of partner associations. The results achieved were able to respond to the established objectives. It was found that there was more positive feedback regarding the impacts caused by the apprentice program both on the lives of the young participants and o the stakeholders and brand linked to them, as well as the intermediary agent.
\end{abstract}

Keywords: Social Marketing. Branding. Stakeholders 


\section{Introdução}

Hoje, o marketing assume um papel crucial na construção da relação entre a empresa e os seus clientes, de modo a possibilitar que olhem de forma pessoal para a empresa em questão e que essa consiga diferenciar-se das restantes, não só prestando serviços e vendendo os produtos, mas sim criando sensações.

O marketing não só poderia ser usado na venda, oferta e promoção de produtos e serviços, mas também em causas sociais, vendendo ideias, comportamentos e mudanças de atitude que promovam o bem estar da sociedade em geral.

Para isso, surgiu o marketing social, que vai para além da preocupação em divulgar produtos ou serviços atrelados a uma empresa ou marca, pois procura transmitir mensagens de conscientização, causar transformações sociais, de comportamentos ou compartilhar ideias que melhorem a convivência da sociedade.

O marketing social pode ser definido como ferramenta estratégica de uma empresa ou marca uma questão ou causa social relevante, em benefício mútuo (SILVA; MINCIOTTI; GIL, 2013). Ou seja, consiste no conjunto de atividades, técnicas e estratégias que são utilizadas para estimular a promoção de mudanças na sociedade, como alterações de atitudes e comportamentos (MARTINS et al., 2014; BARBOZA; COSTA, 2014). Portanto, o marketing social tem como finalidade mudar o comportamento humano através das causas sociais.

Corroborando com os conceitos de Barths e Baldissera (2015), tem-se que o branding é o gerenciamento de marcas, pelo qual as organizações podem atingir objetivos, expandir e manter-se no mercado, sendo que esse processo de gerenciamento se apresenta como uma ferramenta essencial na construção do valor da marca.

A marca é tudo o que se relaciona com a sua propagação, desde um mero uniforme e o logotipo estampado nele, até o impacto social que ela possa causar. É um meio de diferenciar os produtos e serviços de uma empresa dos seus concorrentes. Assim, o branding é essencial para os stakeholders atuais e futuros.

Para Evans (2013), a prática do branding para comportamentos sociais tem sido cada vez mais comum, e se tornou uma abordagem central no marketing social. Portanto, uma estratégia adequada de branding em programas de marketing social pode favorecer o sucesso da iniciativa.

As empresas variam no foco com os stakeholders - algumas se concentram em seus funcionários e clientes, outras, nos seus canais. Todavia, em última análise, o foco deve estar em satisfazer as partes interessadas, independente da classificação.

A palavra stakeholder apareceu pela primeira vez na literatura em um memorando interno do Stanford Research Institute, em 1963 e foi conceituada como "aqueles grupos sem o suporte dos quais a organização deixaria de existir" Freeman (apud FONSECA et al., 2016, p.3). No contexto dessas abordagens, tem-se que a implementação de programas de aprendizagem contribuem para um sólido crescimento das organizações, fortalecimento de suas marcas e estreitamento das relações com seus stakeholders.

$\mathrm{Na}$ perspectiva de analisar o cenário envolvendo o marketing social, a gestão de marcas (Branding) e a relação das organizações com seus stakeholders, a pesquisa estabeleceu como objetivo geral: Analisar a influência do marketing social, direcionado ao programa jovem aprendiz do CIEE Boa Vista - RR, no branding e na relação com os stakeholders da instituição, e como objetivos específicos: Verificar como o marketing social contribui para a inserção 
do jovem no mercado de trabalho através do programa aprendiz; Avaliar estratégias que conduzem a conscientização dos parceiros quanto à contratação de jovens aprendizes; Identificar os motivos que causam resistência na contratação dos jovens aprendizes pelos stakeholders e observar a atuação do jovem aprendiz nas organizações cedentes e sua contribuição com objetivos e metas da organização.

\section{Marketing e Marketing Social}

A principal contribuição do marketing social advém da percepção de valor que o indivíduo adquire ao adotar um comportamento estimulado, conseguindo, assim, alcançar a mudança social direcionada a certo público alvo (BARBOSA; COSTA, 2014).

O marketing social inicia-se como uma verdadeira forma de exercício de responsabilidade social, e pode chegar a construir a longo prazo um valor diferencial para a marca e uma vantagem competitiva para as empresas.

Hoje em dia existem conhecimentos e técnicas para organizar e colocar em prática programas efetivos de mudança social em qualquer área de assunto social, tanto local como nacional. Originar a mudança social que melhore a qualidade de vida da população é um desafio das campanhas sociais e o objetivo do marketing social.

Segundo Hacker (2018), para dominar a arte do marketing de valor agregado, uma empresa precisa entender a personalidade do seu comprador (cliente mais típico) e o que pode ser importante para essa pessoa. Este passo é crucial para decidir o valor do valor que uma marca pode oferecer aos clientes.

Uma vez que um valor agregado potencial é definido, ele deve estar bem integrado no coração de um conceito de negócios. Significa que, o valor agregado deve estar perfeitamente alinhado com a missão, o posicionamento e os objetivos de longo prazo da empresa. O que é oferecido como um valor agregado nunca deve contradizer com o principal produto ou serviço que uma empresa oferece (HACKER, 2018).

O marketing social utiliza dos princípios do marketing tradicional direcionado às causas sociais. O objetivo dessa ferramenta é estabelecer o bem estar social e incentivar uma importante mudança positiva e ética no comportamento da sociedade. Entende-se que o marketing social está focado em criar mudanças nos pensamentos e formas de agir das pessoas, criando novas ideias e emoções, a fim de estabelecer benefícios mútuos.

\section{Branding: aspectos conceituais}

Com a alta competitividade característica dos dias atuais, a gestão estratégica de Marcas, também denominada Branding, passou ser fundamental para a sobrevivência de novos negócios, principalmente em mercados maduros. Pode-se denominar Branding como o conjunto de atividades relacionadas ao gerenciamento das marcas. Atividades ou ações que ordenadas e gerenciadas com inteligência e competência podem levar marcas a obter resultados econômicos.

De acordo com Kotler e Keller (2013, p. 258), os sinais mais antigos de branding na Europa eram as exigências das associações medievais de que os artesãos colocassem marcas em seus produtos para protegerem a si mesmos e aos consumidores contra produtos de qualidade inferior. Nas belas-artes, o branding teve início quando os artistas passaram a assinar suas obras. Hoje em dia as marcas representam diversos papéis importantes que melhoram a vida dos consumidores e incrementam o valor financeiro das empresas. 
Para Wheeler (2013), o branding é um processo disciplinado desenvolvido pelas empresas para conscientizar e aumentar a lealdade dos clientes. Nota-se que o branding não informa apenas os stakeholders externos à organização acerca dos seus valores, mas também tem a função de instruir e direcionar os seus membros. Nesse sentido, as atividades de branding podem ser vistas como práticas de gestão de liderança (ALIZADEH et al, 2014).

O branding tem a ver com a apreensão de cada oportunidade que permita expressar a razão pela qual as pessoas devem escolher uma marca em detrimento de outra. A autora Wheeler (2013), afirma que o desejo de liderar, ultrapassar os competidores e propiciar aos colaboradores ferramentas ideais para o alcance dos consumidores são as razões que levam as empresas a desenvolverem as suas estratégias de branding.

Tendo em vista que a marca consiste em um meio para identificação e diferenciação do produto ou serviço, Scharf et al (2013) apontam que os estudos sobre a gestão da marca ampliam o desempenho, considerando, para isso, entender os efeitos do valor de marca em uma estratégia mercadológica de valor. Nessa perspectiva, os elementos essenciais do valor de marca - ou brand equity - são compreendidos como um instrumento mediador da estratégia e também da identidade de marca estabelecida pela organização.

\section{Stakeholders: organização e influência na construção da estratégia}

De acordo com Harrison et al (2015), a Teoria dos Stakeholders é necessária para fornecer uma perspectiva mais equilibrada nos objetivos das organizações e no gerenciamento para alcançá-los. As empresas podem ser gerenciadas tendo em conta não só os interesses dos proprietários, mas também os interesses de todos os outros Stakeholders, dando origem ao início do gerenciamento destes (RETOLAZA, 2015).

Melo, Bellen e Zaro (2015) ressaltam que os stakebolders são um conjunto de indivíduos interessados nas atividades de uma organização. Por sua vez, Harrison, Freeman e Abreu (2015) destacam esses agentes ou grupo de stakeholders como sendo os colaboradores, administradores, acionistas, financiadores, clientes e fornecedores.

Na perspectiva de Orsiolli e Nobre (2016), garantir a sobrevivência das organizações, requer o reconhecimento dos stakebolders que possuem interdependência direta e indireta, de modo a promover ações que atendam suas expectativas, isso irá criar o sentimento de valor e são incentivados a cumprir o seu propósito de acordo com a gestão centrada no relacionamento estabelecido sustentável entre todas as partes.

O sucesso de uma empresa prestadora de serviços está diretamente relacionado à participação de seus stakeholders; portanto, é necessário assegurar que seus anseios e necessidades sejam conhecidos e considerados pela organização. Se uma empresa arquiteta e põe em prática seus planos de marketing sem levar em consideração todas as variáveis, as quais podem estar sob seu controle ou não, ela erra. Como é impossível prever qualquer comportamento dos stakeholders, qualquer estratégia deliberada de marketing ficará sujeita a falhas, tendo a empresa que adotar de estratégias emergentes.

Schiavoni et al (2013) citam que os stakeholders possuem ligação com a organização e também entre si, por meio de uma rede, como por exemplo, um determinado assunto pode reunir vários stakeholders, podendo a organização conseguir apoio ou não em relação ao seu objetivo. Os stakeholders podem pertencer a mais de um grupo e por isso as empresas devem equilibrar (ou não) os interesses e conflitos. 


\section{Procedimentos metodológicos}

Esse estudo possui abordagem qualitativa e quantitativa, pois além de se preocupar com o aprofundamento e compreensão de uma organização e os seus stakeholders, grupo social que a rodeia, utilizou métodos matemáticos para tratamento das informações oriundas da entrevista estruturada, pela necessidade de obtenção de percentuais de respostas.

Segundo Prodanov (2013), há uma relação dinâmica entre o mundo real e o sujeito, isto é, o pesquisador mantém contato direto com o ambiente e o objeto de estudo em questão, necessitando de um trabalho mais intensivo de campo.

Os objetivos foram descritivos e caracterizaram uma determinada população, estabelecendo relações entre diferentes variáveis, procurando descrever como o marketing social é uma ferramenta influenciadora na busca pela captação e retenção de parcerias. Optou-se pela realização de estudo de um único caso, a fim de investigar em profundidade os fenômenos elencados nos objetivos de pesquisa estabelecidos, assim como a problemática central. A pesquisa foi desenvolvida no Centro de Integração Empresa Escola - CIEE, unidade Boa Vista-Roraima, uma associação civil de direito privado, sem fins lucrativos e de fins não econômicos, reconhecida como entidade de assistência social que, por meio de diversos programas, dentre eles o de aprendizagem, possibilita aos adolescentes uma formação integral, ingressando-os no mercado de trabalho.

Ao longo de seus 56 anos de existência, vêm preparando jovens que buscam o seu primeiro emprego, promovendo acesso, integração ao mundo do trabalho e qualificação dos jovens em encontros de capacitações socioprofissionais.

A Lei da Aprendizagem Profissional se efetivou para que os jovens tenham a primeira oportunidade no mundo de trabalho formal. Para tanto, é importante a empresa que aceita o desafio de orientar o adolescente aprendiz, para que ele tenha o conhecimento do objetivo do Programa, não somente implantar a contratação, mas também contribuir para a formação pessoal e profissional deste adolescente (SCOLARO, 2013).

Atua na profissionalização dos aprendizes, jovens de 14 a 24 anos, que participam da aprendizagem, instituto destinado à formação técnico-profissional metódica de adolescentes e jovens, desenvolvida por meio de atividades teóricas e práticas que são organizadas em tarefas de complexidade progressiva. Tais atividades são implementadas por meio de um contrato, com base em programas organizados e desenvolvidos sob a orientação e responsabilidade de entidades habilitadas (Lei no 8.069/90 Art. 62 e CLT Art. 428).

Nesta análise, recorreu-se a pesquisa de campo por tratar-se da coleta de dados feita nas condições naturais em que o fenômeno ocorreu, sem a intervenção do pesquisador. Assim, foi possível obter informações claras e precisas sobre o evento pesquisado.

O campo da pesquisa foi analisado por meio de um estudo de caso único do Centro de Integração Empresa Escola - CIEE Boa Vista-RR. O critério de seleção de tal agente deu-se pela fácil acessibilidade, pelos 17 anos de experiência do mesmo como integrador de aprendizagem e pelo reconhecimento da marca no estado de Roraima. Recorreu-se à observação direta realizada por meio de análise em duas organizações parceiras do Centro de Integração Empresa Escola - CIEE Boa Vista/RR. A observação é uma técnica que foi utilizada para coletar os dados com o objetivo de conseguir informações que utilizam os sentidos humanos para que fosse possível alcançar 
os aspectos da realidade que se desejava estudar. Foi necessário ouvir, ver e examinar os fatos e fenômenos que estavam ao redor do objeto de estudo.

Assim, foi utilizado um formulário para registro dos dados e informações exclusivas, não constantes na entrevista, no ambiente das organizações cumpridoras da cota de aprendizagem, devido à necessidade de observação espontânea dos fatos. O processo de observação foi realizado no período de janeiro a fevereiro de 2019.

Adotou-se ainda a pesquisa documental, com a investigação de documentos como periódicos, boletins, manuais legislativos e instrutivos da instituição, a fim de levantar informações que pudessem contribuir com a análise do objeto.

Empregou-se os métodos de entrevista estruturada, com objetivo de pré-estabelecer um roteiro de questões que foram respondidas pelas organizações parceiras e aprendizes que foram tomados por amostragem. Aplicou-se ainda o método de entrevista semiestruturada, no qual supervisora e consultora de atendimento do Centro de Integração Empresa Escola participaram de uma entrevista dirigida, mas conduzida com maior flexibilidade, sendo possível incluir novos questionamentos, não planejados, em seu decorrer.

Foram entrevistados 44 jovens aprendizes de diferentes idades, gêneros e classe social e 15 empresas contratantes. Para a realização da entrevista semiestruturada, foi necessária a participação de 2 colaboradoras, sendo essas a supervisora da unidade e consultora de atendimento, ambas responsáveis por fazer visitas de manutenção e firmar novas parcerias para o agente intermediador.

A análise dos dados, sua interpretação e as discussões técnicas foram conjugadas, adequando-se aos objetivos do trabalho, ou seja, foram analisados os conteúdos das entrevistas realizadas com os atores participantes, os documentos institucionais, assim como os fenômenos registrados, coletados no procedimento de observação. $\mathrm{Na}$ medida em que se buscava elucidar os objetivos formulados, as fontes de evidências eram esmiuçadas, a fim de confrontar dados, confirmar, e mesmo rechaçar. Os dados oriundos de tais fontes de evidências foram analisados e relacionados com as teorias pertinentes que subsidiaram a discussão dos resultados e as considerações finais. Assim, segundo Prodanov (2013), essa etapa representa o momento em que o pesquisador obtém os dados coletados por meio da aplicação de técnicas de pesquisa, usando instrumentos específicos para o tipo de informação que deseja obter, de acordo com o objeto de pesquisa em análise.

\section{Apresentação e análise dos resultados}

\section{Contribuições do marketing social na inserção do jovem aprendiz no mercado de trabalho}

O Programa Jovem Aprendiz, enquadrado como um estágio na modalidade da aprendizagem é considerado uma atividade profissional que prepara o jovem para a inserção no mercado de trabalho. Nesse sentido, procurou-se compreender o posicionamento e percepção das organizações abordadas em relação ao Programa "Jovem Aprendiz", visto que as mesmas (sobretudo as de médio e grande porte), não aderem voluntariamente ao programa, mas sim, por imposição da legislação pertinente, pelo que se pôde apurar nos procedimentos de observação informal. Diante disso, realizou-se entrevista com os encarregados pela seleção e contratação dos jovens aprendizes nessas organizações. Os dados revelaram que dos 15 stakeholders entrevistados, 14 consideraram que os aprendizes contribuem de forma positiva com os resultados e alcance dos objetivos propostos. 
Percebeu-se que os stakeholders parceiros do agente intermediador são influenciados pelo apelo social do programa Jovem Aprendiz, embora tenha-se constatado sua adesão por força da legislação. E percebeu-se ainda que há reconhecimento das funções desempenhadas por esses menores. Pôde-se inferir com isso, que há contribuição do programa no processo de inserção do aprendiz no mercado de trabalho.

Durante o procedimento de observação direta, percebeu-se que os aprendizes se integraram facilmente às equipes de trabalho que convivem, tendo um relacionamento amigável com seus chefes imediatos e a partir disso, maior facilidade para desenvolver as atividades na organização.

Os fenômenos coletados em campo, levaram a confirmar que o marketing social pode ser definido como ferramenta estratégica de uma empresa ou marca, uma questão ou causa social relevante, em benefício mútuo (SILVA; MINCIOTTI; GIL, 2013). Consiste no conjunto de atividades, técnicas e estratégias que são utilizadas para estimular a promoção de mudanças na sociedade, como alterações de atitudes e comportamentos (MARTINS et al, 2014; BARBOZA; COSTA, 2014).

O marketing social tem como finalidade mudar o comportamento humano através das causas sociais. O que se percebeu durante a coleta de dados em campo é que o Programa Aprendiz incentiva os jovens a ingressarem no mercado de trabalho e intenciona impedi-los de abandonar os estudos, sendo essas uma das condições para permanência no programa.

\section{Influência do agente intermediador na conscientização dos parceiros quanto ao programa jovem aprendiz}

O trabalho de divulgação e reforço de imagem realizado pelo CIEE tem sido positivo e servido de incentivo não só a contratação dos jovens, mas a conscientização das empresas quanto ao significado do programa e impacto que isso tem na vida pessoal dos jovens.

Segundo Auriani (2019), esse processo de transferência de imagem envolvendo empresa e causa social é possível quando a marca acredita nesta ação e a reconhece como sendo uma ação transformadora para o seu campo de atuação e principalmente se está agindo de maneira ética e socialmente responsável.

Para que isto ocorra, ainda na perspectiva do mesmo autor, a empresa deve privilegiar o desenvolvimento de relacionamentos duradouros entre todos os seus públicos internos e externos, ao mesmo tempo em que evidencia suas ações, através da mensuração do impacto que isso pode causar junto à sociedade.

Apesar do retorno positivo, a entrevista com os stakeholders revelou que ainda precisam ser melhorados alguns pontos, no que tange as estratégias de prospecção de empresas e manutenção do relacionamento com essas parcerias firmadas, pois conforme retorno de um dos entrevistados que discordaram de pontos relacionados ao assunto, o CIEE após firmar a parceria deve estar preparado para receber o jovem no sentido estrutural e psicológico antes mesmo de encaminhá-lo para a empresa, realizando pré-triagens que facilitarão a empresa na escolha do aprendiz que melhor se adeque as regras da organização.

No entanto, para execução de tal processo com sucesso, é necessário que os stakeholders mantenham o acompanhamento social e psicológico do jovem no tempo em que este fica a serviço da organização, tendo em vista que o trabalho de ambas as partes contribuirá para melhoria e evolução do jovem. 


\section{Aspectos do branding do agente intermediador}

O envolvimento das organizações com seus grupos de interesses requer conhecimento para que se tenha uma relação que seja construtiva e produtiva para os envolvidos no negócio.

Para inserir a marca CIEE na mente de alguns de seus stakeholders (empresas cumpridoras da cota de aprendizagem) e conseguir a lealdade, confiança e crença no serviço que lhes é prestado, a empresa utiliza estratégias como consultorias de atendimento, orientações explicativas referentes à importância do programa, que, contribuirão positivamente para a divulgação da marca no mercado.

A partir desse fim, procurou-se saber quais as estratégias relacionadas ao marketing social, são utilizadas pelo CIEE, para conscientização das empresas sobre o programa jovem aprendiz e obteve-se a seguinte reposta da gestão do agente:

"Apresentar a proposta social do programa e alinhá-la com a vulnerabilidade social, perfil da maioria dos jovens que concorrem as vagas disponibilizadas. Ou seja, é importante deixar claro a oportunidade que está sendo concedida ao jovem. O lado emocional verdadeiro é repassado a empresa para que toque além do profissional e entenda o que está sendo tratado. Ao entrar na empresa, com a oportunidade dada, muitas coisas mudam na vida do jovem, para melhor, desde o comportamento até a estrutura familiar".

Diante desse relato, fica claro que uma das estratégias de prospecção utilizadas remetem ao conhecimento da personalidade com quem está sendo realizada a negociação e a partir disso atingir o lado emocional deste, fazendo com que tal empresa entenda o benefício que irá gerar ao dar esse tipo de oportunidade, ainda mais para jovens. Segundo Araújo e Moura (2014), a construção do valor da marca se demonstra importante, pois vai definir como o consumidor vai captar, entender e interagir com a marca e seus atributos de maneira correta.

Além de uma simples tipologia agregada a um desenho, há muitos outros itens mais subjetivos que são divulgados, incluindo um bom atendimento, a velocidade nos serviços, qualidade nos produtos etc. Dois itens precisam estar bem alinhados na comunicação desse valor para que se alcance um patamar bem definido na cabeça do públicoalvo: identidade e imagem da marca.

A partir desse princípio, procurou-se saber se o Centro de Integração Empresa Escola - CIEE influenciou na escolha pelo agente intermediador, e de que forma isso aconteceu durante a contratação de aprendizes: A análise das respostas revelou que todos os stakeholders entrevistados aderiram ao programa aprendiz através do CIEE devido a facilidade de acesso às ferramentas durante os processos de contratação dos jovens desenvolvido pelo agente.

De acordo com informações do periódico Revista Institucional Agitação (2017), além de desenvolver projetos e ações que contextualizam os conteúdos dos cursos, o CIEE promove atividades que instigam a busca do conhecimento, a socialização e a integração dos grupos. Como consequência, fortalece os conceitos de solidariedade, liderança, trabalho em equipe - habilidades demandadas pelas empresas.

A partir disso, a supervisora e a consultora da instituição afirmam que utilizam estratégias de marketing social que facilitam a negociação e convencem os stakeholders a efetuarem as contratações dos jovens aprendizes, entre eles o 
reforço da imagem desses, o apelo social vinculado a marca com a adesão ao Programa e a contribuição que as atividades desenvolvidas pelos jovens trás para os processos das empresas:

"Os benefícios que o CIEE oferta são apresentados durante as visitas de prospecção como diferencial quando comparado a outros agentes, pois as empresas desconhecem as atividades e a proposta que o programa de aprendizagem do CIEE oferece e quando lhes é apresentada convence a empresa a firmar a parceira. As estratégias utilizadas para manter o relacionamento com os parceiros são as visitas de manutenção feitas constantemente. Deve ser dada uma atenção especial aos clientes que são maiores, com uma quantidade significativa de aprendizes ativos".

Conforme relato acima, vê-se que é direcionada uma atenção especial aos convênios/parcerias que possuem maior quantidade de jovens ativos. Isso demonstra uma diferença no tratamento da carteira de clientes, fazendo com que os parceiros com menos aprendizes ganhem uma atenção menor, o que pode ocasionar impactos negativos para o CIEE, como por exemplo: migração do cliente para um novo agente, quebrando o vínculo de relacionamento existente.

Percebe-se que a propagação do Programa Aprendiz, bem como a adesão pelos parceiros, agrega valor à marca do CIEE, abrindo oportunidades para firmação de futuras parcerias.

Para Evans (2013), a prática do branding para comportamentos sociais tem sido cada vez mais comum, e se tornou uma abordagem central no marketing social. Portanto, uma estratégia adequada de branding em programas de marketing social pode favorecer o sucesso da iniciativa, como também mostrado por Evans, Holtz e Snider (2014), quando examinaram uma campanha voltada para a juventude, contra o abuso de drogas. O mesmo raciocínio pode ser usado para campanhas internas nas organizações e em programas de inserção social do jovem no mercado de trabalho, como o aprendiz legal.

As marcas precisam não só transmitir uma imagem "rotulada" do desenvolvimento social, mas devem ter em sua identidade o DNA social, transparecendo a integridade e autenticidade em suas ações para conquistar a confiança e vantagem competitiva no mercado.

As marcas são um meio de diferenciar os produtos e serviços de uma empresa dos seus concorrentes. Assim, o branding é essencial para os stakeholders atuais e futuros.

A partir desse propósito, o CIEE desenvolve atividades de prospeç̧ão do Programa Aprendiz, com o objetivo de convencer as empresas a firmarem parceria a partir do entendimento da proposta social do programa e comoção com as histórias de jovens participantes do programa.

Para Lefebvre (2013) é importante ressaltar que o marketing social precisa propiciar relacionamentos positivos para as duas partes, como o governo e o cidadão, relacionando-se a troca de valores que costumam não ser econômicos, a exemplo de satisfação, auxilio e boas atitudes para qualidade de vida. É preciso um programa que tenha por finalidade envolver todos os âmbitos da sociedade (indivíduos, líderes comunitários e o governo), para que seja possível obter resultados benéficos, além de garantir abordagem auxiliar (educação, comunicação e legislação) (REZENDE et al, 2015). 
A marca desenvolvida pela organização deve estar ligada à cultura e valores defendidos e praticados por esta, de forma a resultar em uma identidade sólida e duradoura a ser comunicada aos seus stakeholders. Nesse sentido, a forma como a identidade da organização é concretizada em uma marca, é caracterizada naquilo que se designou chamar de branding. O branding consiste em gerir a relação entre a organização e os seus stakeholders.

Para Wheeler (2013), o branding é um processo disciplinado desenvolvido pelas empresas para conscientizar e aumentar a lealdade dos clientes. Nota-se que o branding não informa apenas os stakeholders externos à organização acerca dos seus valores, mas também tem a função de instruir e direcionar os seus membros. Nesse sentido, as atividades de branding podem ser vistas como práticas de gestão de liderança (ALIZADEH et al., 2014).

\section{Considerações finais}

Por meio da pesquisa bibliográfica desenvolvida, aprofundou-se os conhecimentos nas diversas áreas em que o marketing atua. Mesmo que, por várias vezes o termo seja ligado a uma situação empresarial que busca vendas e, consequentemente, lucratividade, o estudo destacou outras finalidades para as ferramentas já conhecidas. Com isso em mente, pode-se pontuar o marketing social como exemplo desse propósito diferente do esperado na utilização das ferramentas já conhecidas de divulgação.

Decorrente do trabalho realizado, foi possível conceituar e compreender as aplicabilidades do marketing e do marketing social, além de estudar, através de levantamentos e de pesquisa bibliográfica, o contexto social do problema identificado. Foi possível, também, conhecer a disparidade entre esse problema e o conhecimento dos aprendizes e empresas com relação ao Programa Aprendiz.

Tendo em vista as respostas obtidas através do levantamento, torna-se claro que o Programa Aprendiz tem contribuído inteiramente para a mudança de comportamento e formação profissional do jovem. Além disso, o número de empresas cumpridoras da cota de aprendizagem ou até mesmo que aderem ao programa sem obrigação contribuem para esse fato.

A produção científica contribuiu para o aumento da visibilidade de tal conteúdo e reflexão na realidade social dos jovens, das empresas parceiras e do CIEE. Aspectos evidenciados pela pesquisa em campo, que destacou as contribuições prática e teórica da investigação, principalmente por reluzir a importância das ações sociais, o processo de relacionamento com parceiros (os stakeholders) e o impacto de tais variáveis para o Branding, tendo em vista o processo de construção de marcas fortes e influenciadoras, com sólido posicionamento de mercado, um status almejado pelas organizações que objetivam resultados em suas operações.

Em síntese, o estudo propicia contribuição para a organização investigada e seus atores, por revelar aspectos implícitos decorrentes de sua relação com seus públicos de interesse e por identificar pontos de atenção passíveis de gerenciamento. Cientificamente, contribui com os estudos no âmbito da mercadologia, por acrescentar um olhar distinto para as estratégias de branding, influenciadas pelo resultado das ações de marketing social, ademais, esse olhar foi para além do que foi observado no contexto do microambiente, pelo fato de ter analisado a perspectiva dos stakeholders - parceiros externos da organização em apreço. Desta forma, tem-se o entrelace desses importantes elementos avaliados como determinantes ao processo de construção da imagem de marca de uma organização, que interage com as áreas: pública, privada e do terceiro setor. 
A completude da análise proposta na pesquisa, sofrera limitações, principalmente pelo fato de não ter contado com a participação de todos os stakeholders da instituição. Houve limitações de tempo e ainda, a não concordância ou desinteresse de parceiros que não participaram da pesquisa. Em relação aos Jovens Aprendizes que foram entrevistados, observou-se o fato de que pela imaturidade (a maioria dos respondentes da entrevista possuía entre 15 e 20 anos), possivelmente as respostas concedidas não correspondiam à realidade. Ademais, deve-se considerar ainda, o temor pela perda de sua oportunidade de trabalho (mesmo que o procedimento de coleta de dados em campo tenha previsto o gerenciamento dos riscos para o pesquisador, organização e participantes da pesquisa).

Todavia, acredita-se que os resultados apresentados foram satisfatórios aos objetivos previstos inicialmente. Assim, pode-se inferir que a pesquisa contribui no conhecimento da questão da identidade de marca, bem como do processo de comunicação de marketing social entre o agente intermediador e os stakeholders.

O contexto social acerca do trabalho apresentado foi o primeiro motivador para a conclusão dessa pesquisa. Por conta disso, espera-se que mais trabalhos de marketing social sejam realizados em prol do jovem trabalhador, principalmente destacando a importância de inclusão dos mesmos no mercado de trabalho. Nesta perspectiva, descortina-se um diversificado leque de oportunidades para pesquisas futuras, com olhares direcionados ao jovem aprendiz, como principal ator do marketing social - considerando o contexto das agências intermediadoras de oportunidades de trabalho/emprego. Vislumbra-se ainda a possibilidade de futuros ensaios tendo como lócus de investigação, organizações públicas e privadas, a fim de identificar a forma como se desenvolvem as ações de marketing social, a contratação de jovens aprendizes e a influência desses aspectos no branding.

Tendo como base a problemática do estudo (De que forma o marketing social direcionado ao programa Jovem Aprendiz do CIEE Boa Vista - RR, influencia o branding e a relação com os stakeholders da instituição?), conclui-se que o Programa Aprendiz agrega valor, oferecendo pano de fundo para a política de marketing do Centro de Integração que pelo uso de métodos de divulgação que viabilizem a fundamentação do programa para as organizações parceiras, contribui para que essas compreendam o significado do programa por trás das cotas de aprendizagem.

Isto posto, acredita-se que há contribuição do programa para estratégia de branding da instituição em apreço e que uma vez atendidas as expectativas dos parceiros, neste trabalho intitulados stakeholders, poderá haver contrapartidas importantes no que tange ao brand equity, pavimentando caminhos para elaboração e implementação de estratégias de marketing social.

Nessa perspectiva, a Lei do Aprendiz poderá proporcionar diversos benefícios. A garantia da educação, aliada ao conjunto educação profissional e empresa, permite que o jovem ganhe experiência profissional compatível com o seu desenvolvimento, auxiliando na sua qualificação profissional, além de fortalecer a proteção contra a exploração no trabalho. Para as empresas, garante a sua atuação com marketing social e investimento na formação de novos profissionais.

\section{Referências}


ALIZADEH, A., HOSEINI, S. e NAIEJ, A. (2014). The Comparison of Product and Corporate Branding Strategy: a conceptual framework. Journal of Business and Management, vol. 16, p. 14-24. Disponível em: http://scriptiesonline.uba.uva.nl/document/656574. Acesso em 11 de nov. 2018.

ARAÚJO, Ana Beatriz Alves; MOURA, Davi Jeremias da Silva. Marca, posicionamento e Brand Equity: um levantamento teórico. Tecnologia \& Informação, v. 1, n. 3, p. 7-19, 2014.

AURIANI, Márcia. Branding Social. InfoBranding: inteligência em gestão de marcas, 2019. Disponivel em: http://www.infobranding.com.br/branding-social/ Acesso em 24 de maio de 2019.

BARTHS, G.;Baldissera, R. Branding e a rede de organizações por articulação conceitual. BrandTrendsJournal, v.9, n.9, p. 70-86, 2015.

BARBOSA, S. I. S.; COSTA, F. J. Marketing social para Doação de Sangue: análise da predisposição de novos doadores. Cad. Saúde Pública, v. 30, n. 7, p. 1463-1474, 2014.

EVANS, W. D., Holtz, K.; Snider, J.. Effects of the Above the Influence Brand on Adolescent Drug Use Prevention Beliefs. Journal of Health Communication, v. 19, n.6 , p. 721- 37, 2014.

FONSECA, Patrícia. FERNANDA, Jeniffer. WALTER, João. MONTEIRO, Marly. Gerenciamento de Stakeholders em Projetos: Um Estudo em uma Empresa de Serviços. In: V SINGEP - Simpósio Internacional de Gestão de Projetos, Inovação e Sustentabilidade, São Paulo, 2016.

HACKER, Neto. Os conceitos básicos do marketing de valor agregado. 2018. Disponível em: https://netoangel.com/marketing-de-valor-agregado, acesso em 20 jun 2020.

HARISSON, J., Freeman, E.; Abreu, M. C. S. Stakeholder theory an ethical approach to effective management: Applying the theory to multiple contexts. Revista Brasileira de Gestão de Negócios, v.17, n,55, p. 858-869, 2015.

HE, H., Zhu, W., Gouran, D. ; Kolo, O. Moral identity centrality and cause-related marketing: The moderating effects of brand social responsibility image and emotional brand attachment. European Journal of Marketing, v.50, n.1/2, p. 236-259, 2016.

INSTITUTO ETHOS, Perguntas frequentes. Recuperado de http://www.ethos.org.br, 2015. Acesso em 15 jun $\underline{2020 .}$

KOTLER, Philip; KELLER, Kevin Lane. Administração de Marketing. 14 ed. São Paulo: Pearson Education do Brasil, 2013.

LEFEBVRE, H. Le Droit à la Ville. Paris: Anthropos, 2013.

MARTINS, O. M. D.; PAÇO; A. M.; MAINARDES, E. W.; RODRIGUES, R. G. O marketing social e a promoção de mudanças estruturais no aleitamento materno. Revista de Administração de Empresas - ERA, v. 54, n. 4, p. 370-380, 2014.

MELO, P. T. N. B., Bellen, H. M. V., \& Zaro, E. S. A qualidade do capital social com stakeholders: Fator de desenvolvimento espúrio ou sustentável. Revista de Gestão Ambiental e Sustentabilidade. v. 4, n.2, p. 1-17, (2015).

ORSIOLLI, Thálita Anny Estefanuto; NOBRE, Farley Simon. Empreendedorismo sustentável e stakeholders fornecedores: criação de valores para o desenvolvimento sustentável. 2016 Universidade Federal do Paraná. RAC, Rio de Janeiro, v. 20, n. 4, art. 6, jul.-ago. 2016.

PRODANOV, Cleber Cristiano. Metodologia do trabalho científico [recurso eletrônico]: métodos e técnicas da pesquisa e do trabalho acadêmico. 2 Ed. - Novo Hamburgo: Feevale, 2013. 
RETOLAZA, J. L., \& Roqueñi, M. R., Jose, L. S. (2015). An Innovative Approach to Stakeholder Theory: application in spanish transnational corporations. Review of Business Management, v.17, n.55, p.10071020, (2015).

REZENDE, L. B. O. et al. Doação de órgãos no Brasil: uma análise das campanhas governamentais sob a perspectiva do marketing social. Revista Brasileira de Marketing - ReMark, v. 14, n. 3, p. 362-376, 2015.

SCHARF, E. R.; VIEIRA, F. G.D.; KRAUSE, R. Estudos sobre identidade de marca: uma análise sobre a produção acadêmica brasileira de 1997 a 2011-Studies on Brand Identity: anAnalysisoftheBrazilianAcademicProductionfrom 1997 to 2011. GESTÃO. Org-Revista Eletrônica de Gestão Organizacional, v. 11, n. 1, 2013.

SCHIAVONI, P. M. B.; MORAES, M. C. B.; CASTRO, A. C.; SANTOS, J. N.. Stakeholders: Principais Abordagens. Revista de Ciências da Administração, v. 15, n. 37, sep-dic, p. 187-197, 2013.

SILVA, E. C., MINCIOTTI, S. A.; Gil, A. C. Resgatando o conceito de marketing social. Journal of Public Administration \& Social Management, v. 5, n.2, p.135-152, 2013.

WHEELER, A. Designing Brand Identity: Na Essential Guide for the Whole Branding Team. John Wiley \& Sons, Inc., Hoboken, 2013. 